\title{
A Long-term Power Purchase Optimization Method Considering the Equal Completion Progress and Minimize Power Purchase Cost
}

\author{
Cheng Haihua \& Zheng Yaxian \& Xue Bike \& Gen Jian \& Yang Zhenglin \\ Power Automation Dept. China Electric Power Research Institute, Nanjing, China \\ Zhang Ben \& Wang Yang \\ Electric Power Dispatching Control Center, North China Power Grid Company, Beijing, China
}

\begin{abstract}
The current long-term purchase power optimization, mainly consider the equal completion policy requirements, and do not consider the optimization of power purchasing cost. This paper presents a long-term power purchase optimization method, which uses the electricity purchasing cost as the goal, with the equal completion as the constraint, considering the generator load rate, unit maintenance and other constraints. It is MIP model which using provincial data to analysis.
\end{abstract}

KEYWORD: Long term power purchase optimization; Minimize power purchase cost; Equal completion progress

\section{BACKGROUND INTRODUCTION}

\subsection{Introduction}

The current long-term purchase power optimization, mainly consider the equal completion policy requirements, and do not consider the optimization of power purchasing cost. At present, the annual power purchase plan is allocated to each month to ensure that in December all the plant's annual plan is completed with the consistent progress, the deviation between all plant's progress and average progress is not more than plus or minus $3 \%$. In this process does not consider the purchase cost. How to meet the completion progress requirement, at the same time reduce the purchasing cost as much as possible, is an urgent problem to be solved.

\subsection{The domestic and foreign research situation}

In Europe and the United States, the methods of long-term contracts and real time transactions are used in power market.

In China, the electricity market is not mature enough. At present the government department issued the plant's annual plan, and then the annual plan is decomposed into the 12 months, according to the same completion progress requirements. How to reduce the purchasing cost as much as possible, this problem has some relevant research results in China.

Document 1 introduce the conditional value at risk of provincial electricity company purchasing portfolio risk measurement, based on the provincial electric power company portfolio theory under the purchasing portfolio optimization model; Document 2 analyze the current situation of purchase cost and put forward optimization power plans to reduce power purchase cost of power grid model and strength analysis. Article 3 introduces the existence of free purchasing space, and put forward the power purchase optimization model. Article 4 proposes a power purchase plan model taking into account the loss. In the existing research, only Article 2 consider the equal completion progress, but the given deviation model due to determine the energy balance point calculation is complex, it is difficult to practical application, the other articles and documents don't consider the equal completion progress requirements.

This paper puts forward an optimization method which can satisfy the equal completion progress requirements, and reduce the purchasing cost as much as possible at the same time. The method uses provincial data to analysis.

\section{OPTIMIZATION OF MULTIPLE OBJECTIVES}

In accordance with the policies and regulations, the deviation between all plant's progress and average progress is not more than plus or minus $3 \%$. If the electricity whole load is $40000000 \mathrm{MWh}$, we assume the half electricity load borne by the expensive units, half by the low price units, The average deviation of expensive price and low price is $100 \mathrm{Yuan} / \mathrm{MWh}$, we will make the completion progress of the expensive unit $3 \%$, make the completion progress of 
the low price unit negative $3 \%$, it can approximately reduce power purchase costs:

$$
40000000 * 0.03 * 100=120000000 \text { (Yuan) }
$$

Thus, under the equal complete progress limitation, the optimizing space of power purchase cost is relatively large. The long-term power purchase optimization, considering the purchase cost, it is not simple to make the completion progress of the expensive unit 3\%, make the completion progress of the low price unit negative $3 \%$. It is a mixed integer programming problem, considering monthly load balance constraint, load rate constraint, unit maintenance scheduling and so on.

\section{POWER PURCHASING OPTIMIZATION MODEL}

In this paper, the optimization method considering the equal completion progress and power purchase cost is put forward. The optimization objective is the minimum purchase cost, the optimization constraints include the equal completion progress, monthly balance, the maximum load rate of units, the smallest load rate of units, unit maintenance and so on. It use MIP optimization model.

\subsection{Optimization objective model}

Power purchase cost model:

$$
C=\sum_{\mathrm{i}=1}^{\mathrm{I}} \sum_{\mathrm{mon}>=\mathrm{SM}}^{E M} \mathrm{PE}(\mathrm{i}, \mathrm{mon}) * \operatorname{Pr}(i)
$$

$\operatorname{Pr}(i)$ : The energy price of unit ${ }^{i}$;

$P E(i, m o n)$ : The monthly plan energy of unit $i$ in month ${ }^{\text {mon }}$, it is a optimization variable;

$S M$ : The start month of power purchase optimization;

$E M$ : The end month of power purchase optimization;

Through setting the $S M$ and $E M$ parameter, we can get three types optimization object: the power purchase cost of current month, the power purchase cost of current season, the power purchase cost of current year

\subsection{Optimization constraints model}

\subsubsection{The constraint of monthly load energy balance}

$$
L E(\text { mon })=\sum_{\mathrm{i}=1}^{\mathrm{I}} P E(i, \text { mon })
$$

$P E(i, m o n)$ : The monthly plan energy of unit $i$, it is a optimization variable;
$L E(m o n):$ The forecasting monthly load energy;

$I$ : The count of all units;

\subsubsection{The constraint of unit minimize energy}

$$
P E(i, \text { mon }) \geq R_{i}(i, \text { mon }) * \operatorname{MinEng}(i, \text { mon })
$$

If the load rate of any unit is too low, the unit should be stopped, avoiding the unit running in not economical status;

$\operatorname{MinEng}(i$, mon $)$ : The minimize energy of unit $i$ in month mon ;

$R_{i}(i$, mon $):$ The status of the unit $i$ in month ${ }^{\text {mon }}$, 1 express running status, 0 express stopped status, it is a optimization variable.

\subsubsection{The constraint of unit maximum energy}

$$
P E(i, \text { mon }) \leq R_{i}(i, \text { mon }) * \operatorname{MaxEng}(i, \text { mon })
$$

$\operatorname{Max} \operatorname{Eng}(i$, mon $):$ The maximum energy of unit $i$ in month mon, considering the max load ratio of unit $i$, the unit maintenance and so on. The constraint can prevent the unit from running in high load ratio situation, which can hold reserve capacity for power grid.

\subsubsection{The constraint of equal completion progress}

1) The standard completion progress model

$$
\begin{aligned}
& S P(\text { mon })=\left(\sum_{i}^{I} \sum_{p m=1}^{p m<=P M} F E(i, p m)+\right. \\
& \left.\sum_{m o n=P M+1}^{m o n} L E(m o n 1)\right) / \sum_{i} C E(i)
\end{aligned}
$$

$F E(i, p m)$ : The finished energy of unit $i$ in month mon;

$L E(m o n 1)$ : The forecasting load energy;

$C E(i)$ : The year plan energy of unit ${ }^{i}$;

$S P($ mon $):$ The standard completion progress in month ${ }^{m o n}$;

$P M$ : The month before the start plan month.

2)The deviation constraint of completion progress

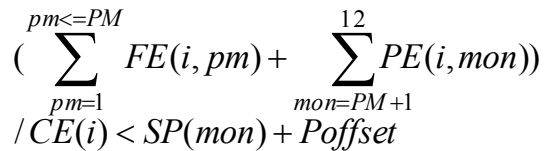

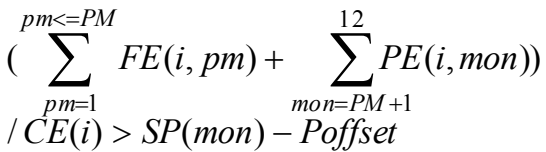

Poffset: The max deviation of completion progress, it is a parameter, it can be plus or minus $3 \%$. 


\section{EXAMPLE ANALYSES}

Case description: The example is based on actual provincial data. There are 64 thermal units, which has capacity of 32000000 kilowatts. We need to optimize monthly unit plan energy from April to December, the considering constraints include: April to December monthly energy balance, unit load rate within the reasonable range (0.6 to 0.85$)$, the unit maintenance scheduling, the unit completion progress deviation does not exceed the limit (here set to plus or minus 0.03). From April to December the monthly power loads list in Table 1.

Table.1 The forecasting load energy

\begin{tabular}{|l|c|}
\hline month & $\begin{array}{c}\text { The forecasting load energy } \\
\text { (hundred million } \mathrm{kWh} \text { ) }\end{array}$ \\
\hline April & 153.96 \\
\hline May & 158.22 \\
\hline June & 159.12 \\
\hline July & 183.96 \\
\hline August & 182.95 \\
\hline September & 163.87 \\
\hline October & 150.30 \\
\hline November & 156.69 \\
\hline December & 171.28 \\
\hline
\end{tabular}

There are three optimization objectives as following:

The first objectives: the minimum power purchase cost of current month;

The second objectives: the minimum power purchase cost of current season;

The third objectives: the minimum power purchase cost of current year.

There are three optimization results as following:

Table.2 Optimization results

\begin{tabular}{|l|c|c|c|}
\hline $\begin{array}{l}\text { Three } \\
\text { optimization } \\
\text { objectives }\end{array}$ & $\begin{array}{l}\text { The power } \\
\text { purchase cost of } \\
\text { current month } \\
\text { (Billion Yuan) }\end{array}$ & $\begin{array}{l}\text { The power } \\
\text { purchase cost of } \\
\text { current season } \\
\text { (Billion Yuan) }\end{array}$ & $\begin{array}{l}\text { The power } \\
\text { purchase cost of } \\
\text { current year } \\
\text { (Billion Yuan) }\end{array}$ \\
\hline $\begin{array}{l}\text { The first } \\
\text { objectives }\end{array}$ & 75.65 & 234.81 & 740.87 \\
\hline $\begin{array}{l}\text { The second } \\
\text { objectives }\end{array}$ & 76.76 & 234.44 & 740.84 \\
\hline $\begin{array}{l}\text { The third } \\
\text { objectives }\end{array}$ & 76.82 & 236.86 & 740.66 \\
\hline
\end{tabular}

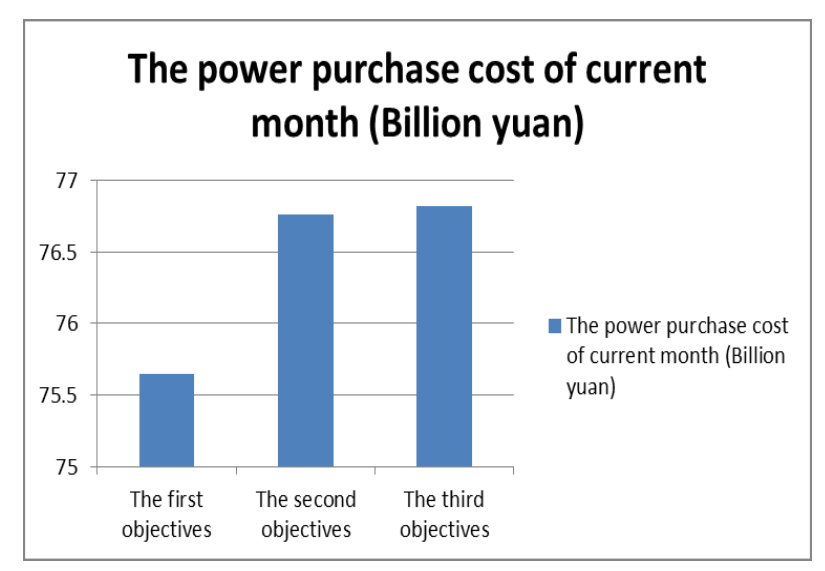

Figure 1. The Comparison of the power purchase cost of current month

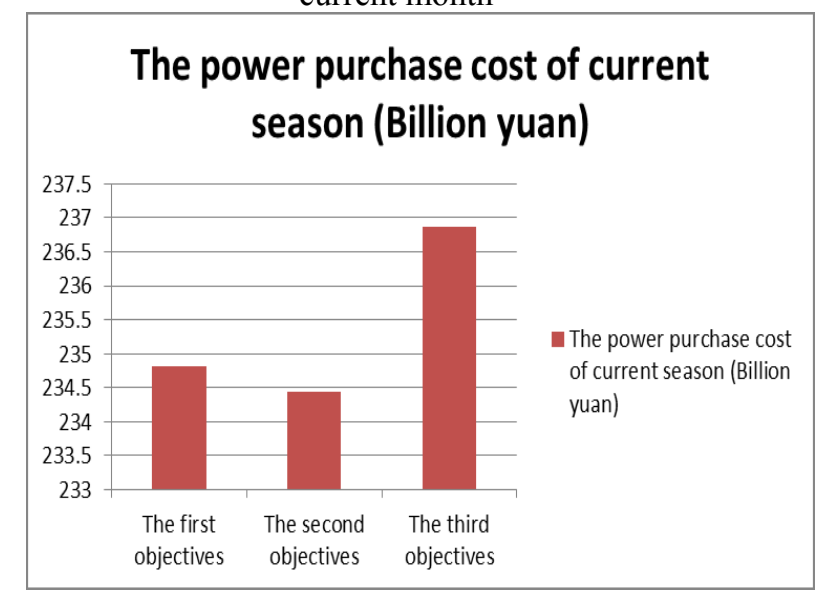

Figure 2. The Comparison of the power purchase cost of current season

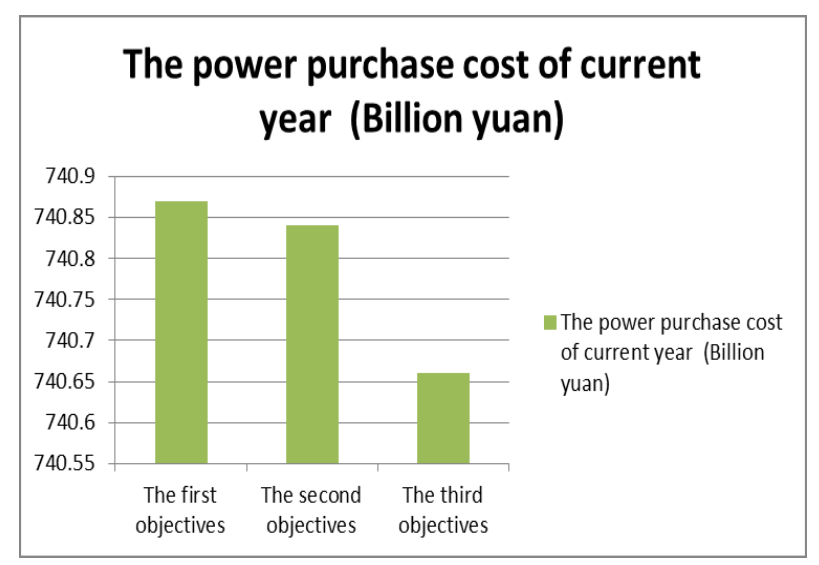

Figure 3. The Comparison of the power purchase cost of current year

Analysis: in the first objectives, the power purchase cost of current month is the lowest, the power purchase cost of current season is in the middle, the power purchase cost of current year is the highest, because in the first objectives, the optimization object is current month, so the power purchase cost of other months is without control, so the power purchase costs of season and year are in the higher situation. Conversely, in the third objectives, the optimization objectives is power purchase cost of current year, so the power purchase cost of current year is the lowest, it saved 21000000 Yuan compared with the first objectives, 
the power purchase costs of month and season are in the higher situation.

Three optimization schemes have their pros and cons, the decision maker can choose one as the ideal solution according to the actual situation.

\section{DEADLINE}

This paper presents a long-term power purchase optimization method, which minimize the power purchase cost considering the equal completion proress. This method is successfully used in a provincial gird company to meet the production demand.

\section{ACKNOWLEDGEMENT}

The work is supported by Project of Scientific and Technical Supporting Programs Funded by North China Power Grid Company, Project Name is "Multi
Days Unit Commitment Optimization Technology Research and Application in North China Power Grid".

\section{REFERENCES}

[1] SHANG Jincheng, WANG Mianbin, TAN Zhongfu, LIU Liping, Purchasing strategy models of provincial gird company and relevant fuzzy optimization algorithms, East China Electric Power, Nov.2008, Vol36, No 11.

[2] CAI Wenqin, ZHANG Sirong, The Model Research of Electric Power Purchase Cost in Power grid Enterprise, Central China Power ,2007,Vo20,No 1.

[3] TIAN Kuo, ZENG Ming, SHI Lianjun, YANG Pengju, Free purchasing space and purchasing optimization strategies for provincial grid companies in market envirioment, East China Electric Power, July 2009, Vol 37, No 7

[4] ZHANG Yong-jun,LIAO Min-chuan,YUAN Wen-gen,LI Bang-feng, Power Purchase Planning of Power Network Company Considering Energy Saving, Proceedings of CSU-EPSA. Dec 2008, Vol20,No 6 